Article

\title{
Synthesis, Property and Mechanism Analysis of a Novel Polyhydroxy Organic Amine Shale Hydration Inhibitor
}

\author{
Weichao Du ${ }^{1,2, * \mathbb{D}}$, Xiangyun Wang ${ }^{1}$, Gang Chen ${ }^{1}$, Jie Zhang ${ }^{1}$ and Michal Slaný ${ }^{3, * \mathbb{C}}$ \\ 1 Shaanxi Province Key Laboratory of Environmental Pollution Control and Reservoir Protection Technology \\ of Oilfields, Xi'an Shiyou University, Xi'an 710065, China; 18298818107@163.com (X.W.); \\ gangchen@xsyu.edu.cn (G.C.); zhangjie@xsyu.edu.cn (J.Z.) \\ 2 State Key Laboratory of Oil \& Gas Reservoir Geology and Exploitation, Chengdu University of Technology, \\ Chengdu 620021, China \\ 3 Institute of Inorganic Chemistry, Slovak Academy of Sciences, Dúbravská cesta 9, 84536 Bratislava, Slovakia \\ * Correspondence: duweichao@xsyu.edu.cn (W.D.); michal.slany@savba.sk (M.S.)
}

Received: 23 November 2019; Accepted: 29 January 2020; Published: 31 January 2020

\begin{abstract}
Based on the adsorption mechanism analysis of polyhydroxy organic compound on a shale surface, a novel polyhydroxy organic amine shale hydration inhibitor $\mathrm{N}, \mathrm{N}, \mathrm{N}^{\prime}, \mathrm{N}^{\prime}$-tetrakis (2-hydroxyethyl) ethylenediamine (THEED) was synthesized via a nucleophilic reaction by using diethanolamine and dibromoethane as raw materials. Its structure was characterized by Fourier transform infrared spectrometry (FTIR), Hydrogen Nuclear Magnetic Resonance $\left({ }^{1} \mathrm{H}\right.$ NMR) and Liquid Chromatography Mass Spectrometry (LCMS). The inhibition performance of THEED was studied by a shale rolling recovery experiment, a linear expansion experiment and the particle size distribution experiment. Results showed the shale rolling recovery rate in $2.0 \mathrm{wt} \%$ THEED solutions was up to $89.6 \%$ at the rolling condition of $100{ }^{\circ} \mathrm{C} \times 16 \mathrm{~h}$, and the linear expansion height of artificial shale core in $2.0 \mathrm{wt} \%$ THEED solutions was just $4.74 \mathrm{~mm}$ after $16 \mathrm{~h}$. The average particle size of Na-bentonite (Na-MMT) in fresh water was $8.05 \mu \mathrm{m}$, and it was observed that the average particle size has been increased to $124 \mu \mathrm{m}$ in $2.0 \mathrm{wt} \%$ THEED solutions. The shale hydration inhibition mechanism of the novel inhibitor THEED was analyzed by FTIR, Scanning Electron Microscopy (SEM) and X-ray diffractometry (XRD), we concluded that the nice shale hydration inhibition performance of THEED was achieved by means of intercalation and adsorption onto the surface of shale. The superior shale hydration inhibition property makes THEED promising in maintaining wellbore stability in drilling engineering.
\end{abstract}

Keywords: polyhydroxy; shale hydration inhibitor; shale gas; drilling fluids; clay; organic amine

\section{Introduction}

China's predicted shale gas reserves are about $10 \sim 47 \times 10^{12} \mathrm{~m}^{3}$, which accounts for $5.7 \%$ of the world total reserves [1]. However, the mineral compositions of shale reservoirs in China are complicated, and hydration dispersion clay minerals, such as montmorillonite (which itself accounts for something in the range from $0 \%-15 \%$ of clay minerals in shale gas reservoirs), are usually encountered in drilling engineering [1]. Shale formations are known for their chemical interactions with water-based drilling muds, which may result in swelling, bit balling, or even closure of the wellbore [2-4]. When there is bentonite-rich shale gas formation exposure in drilling fluids, the strength of the shale gas wellbore will be greatly reduced and borehole instability occurred.

Therefore, the drilling fluids must have excellent shale hydration inhibition ability, in order to ensure the smooth progress of drilling engineering [5,6]. Oil-based drilling fluids (OBDFs) are 
always the best drilling fluids option for drilling shale gas. However, the increasing demands for environmental legislation and excessive costs restrict these OBDFs in drilling applications. Water-based drilling fluids (WBDFs) are simple in their composition, are inexpensive, and the drilling waste is easily accepted by the environment; therefore, the development of WBDFs become an inevitable trend in drilling engineering [7-9]. But, the relatively poor inhibition of WBDFs has limited its application in shale gas drilling [10].

For a long time, a variety of drilling fluids additives generally referred to as 'shale hydration inhibitor' or 'clay stabilizer' have been developed and utilized to ensure the wellbore stability in shale gas drilling [11]. There are two ways by which shale hydration swelling will be inhibited during the drilling engineering; (i) through the intercalation of small organic molecules into the interlayer space of shale, and (ii) through the shale package by high molecular weight polymers [12]. The efficiency testing of a shale inhibitor is as old as the drilling fluids industry itself, and shale-drilling fluids testing remains an active topic of interest for drilling fluids evaluation, as the hydration expansion of shale is mainly caused by the expansive Na-MMT in the shale composition, the evaluation of a shale inhibitor generally by using Na-MMT. When shale inhibitor started to be deliberately utilized for wellbore stability, the reaction of these additives with swelling clay-rich shale formations became immediately apparent, and the oilfield industry has been trying to make sense of it all ever since $[13,14]$.

A recent review by Stephens et al. recommends that the conventional test for different shale inhibitors are atmospheric swelling tests (linear expansion experiment), dispersion tests (hot-rolling test), capillary suction tests, bulk hardness tests, an immersion test and fracture development tests [15,16]. However, considering the economic and practical situation, the hot rolling recovery experiment, linear expansion experiment and particle size distribution experiment are the three usual testing methods in the laboratory. The hot rolling experiments can be used to analyze the ability of a shale inhibitor to inhibit the shale hydration dispersion. A linear expansion experiment is utilized to study the performance to inhibit the shale hydration expansion of inhibitors. The particle size analysis experiment has the function of comprehensively studying the shale inhibitor to inhibit shale hydration expansion and dispersion.

The shale hydration inhibitors which were used in the early stage of the oil industry are inorganic salts, such as potassium chloride, calcium chloride, ammonium chloride, etc. Relatively high amounts of inorganic shale hydration inhibitor are required, with amounts of potassium chloride ranging from 2-15 wt \% typically being necessary to maintain wellbore stability. Some polymer inhibitors, such as asphalt, polymeric alcohols, ammonium salt polymers, zwitterionic polymers, nonionic polymers and cationic polymers have been successfully applied in the past years, and the concentrations of polymer typically being necessary ranging from $0.5 \mathrm{wt} \%-2 \mathrm{wt} \%$ [17]. These inhibitors alleviate the problem of wellbore instability to some extent for a period of time. However, present shale inhibitors still fail to fully meet the safe drilling needs of shale gas drilling at present [18].

Organic amine inhibitors have been proven show a certain shale hydration inhibition property by a large number of experiments [19]. Since the 1960s, small molecular organic amine inhibitors such as $\mathrm{NH}_{4} \mathrm{Cl}$, tetramethylammonium chloride, dimethyldiallylammonium chloride, amine derivative and polyamine have been applied in the past years. However, most organic amines have disadvantages, such as high level toxicity, poor temperature resistance and poor salt resistance performance, and these easily released the harmful gas $\mathrm{NH}_{3}$. The hydroxyl functional groups of molecules can form strong hydrogen bonds with the exposed $\mathrm{OH}(\mathrm{O})$ of shale, thus increasing the adsorption ability of the amine molecule onto the shale surface, which will provide more inspiration to the oil field researcher to design a shale inhibitor molecule [20-22].

What is more, results have shown that low molecular weight polyhydroxy organic amine can enter into the shale crystal layer, compressing the diffusion double layer and becoming strongly adsorbed onto the surface of the shale by the synergistic effect of a hydroxyl group and amine groups. However, few articles have reported the applications of polyhydroxy organic amine inhibitors in WBDFs [14,23]. 
Based on the adsorption mechanism analysis of polyhydroxy compounds on shale and the above review, a novel polyhydroxy organic amine shale hydration inhibitor $\mathrm{N}, \mathrm{N}, \mathrm{N}^{\prime}, \mathrm{N}^{\prime}$-tetrakis (2-hydroxyethyl) ethylenediamine was synthesized via a nucleophilic reaction by using diethanolamine and dibromoethane as our raw materials. Its inhibition performance was evaluated by a shale hot rolling recovery experiment, a linear expansion experiment and particle size distribution experiment. Its shale inhibition mechanism was studied by means of FTIR, XRD and SEM in this paper.

\section{Experimental}

\subsection{Materials}

Diethanolamine, dibromoethane, ethanol, ethyl acetate, anhydrous magnesium sulfate $\left(\mathrm{MgSO}_{4}\right)$, anhydrous sodium carbonate $\left(\mathrm{Na}_{2} \mathrm{CO}_{3}\right)$ and potassium chloride $(\mathrm{KCl})$ were all analytically pure and purchased from Kelon Chemical Reagent Factory, Chengdu, China. NW-1 (a low molecule quaternary ammonium salt shale inhibitor) and mineral oil were provided by the Engineering Technology R\&D Company limited, Beijing, China. Na-MMT was obtained from Xia Zijie Bentonite Technology Co., Ltd, and was used for inhibitor/Na-MMT preparation. The cation exchange capacity (CEC) of Na-Mt was $82 \mathrm{meq} / 100 \mathrm{~g}(0.82 \mathrm{mmol} / \mathrm{g})$. The Na-MMT was suspended in distilled water, Na-saturated by repeated treatment with $1 \mathrm{M}$ Knack, and the $<2 \mu \mathrm{m}$ fraction was collected. The excess of the $\mathrm{Cl}^{-}$ions was removed by washing with distilled water. The sample (Na-Mt) was dried at $60{ }^{\circ} \mathrm{C}$ and ground to pass a $0.2 \mathrm{~mm}$ sieve. The main compounds were of $\mathrm{SiO}_{2} 65.37 \%, \mathrm{Al}_{2} \mathrm{O}_{3} 20.23 \%, \mathrm{Fe}_{2} \mathrm{O}_{3} 3.07 \%, \mathrm{MgO} 3.85 \%$, $\mathrm{Na}_{2} \mathrm{O} 2.65 \%, \mathrm{CaO} 0.81 \%$ and $\mathrm{K}_{2} \mathrm{O} 1.02 \%$. The shale samples were obtained from Fuling Chongqing, and the mineral compositions were illustrated in Table 1.

Table 1. The mineral compositions of shale samples.

\begin{tabular}{cccccc}
\hline Mineral Compositions & Kaolinite & Chlorite & Illite & Sodium Bentonite & Illite/Sodium Bentonite \\
\hline Content $\%$ & 0.0 & 26.3 & 65.1 & 8.6 & 10.0 \\
\hline
\end{tabular}

\subsection{Synthesis and Characterization of THEED}

The prepared steps of $\mathrm{N}, \mathrm{N}, \mathrm{N}^{\prime}, \mathrm{N}^{\prime}$-tetrakis (2-hydroxyethyl) ethylenediamine (THEED) are as follows: $0.2 \mathrm{~mol}$ diethanolamine, $0.1 \mathrm{~mol}$ dibromoethane and $75 \mathrm{~mL}$ ethanol were placed in a round-bottom flask equipped with a reflux condenser and refluxed for $12 \mathrm{~h}$ with magnetic stirring at $45^{\circ} \mathrm{C}$. Then, $0.2 \mathrm{~mol} \mathrm{Na} 2 \mathrm{CO}_{3}$ was added and the reaction was continued for another $4 \mathrm{~h}$. When reaction was finished, insoluble material was removed by filtration, and the ethanol was evaporated by a rotary distillation apparatus. The crude product was extracted with deionized water and ether, and the ether layer was dried with $\mathrm{MgSO}_{4}$ to obtain the viscous product. After removing diethanolamine and ether from the product by vacuum distillation at the condition of $135-137^{\circ} \mathrm{C} / 0.1 \mathrm{~mm} \mathrm{Hg}$, a transparent, yellow final product THEED was obtained with a yield of $75.6 \%$. The synthesis route of THEED is shown in Figure 1.

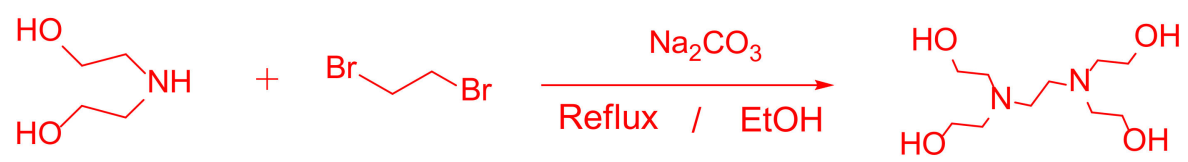

Figure 1. Synthesis route of $\mathrm{N}, \mathrm{N}, \mathrm{N}^{\prime}, \mathrm{N}^{\prime}$-tetrakis (2-hydroxyethyl) ethylenediamine (THEED).

The infrared spectra were collected using the WQF-520 Fourier Transform Infrared (FTIR) spectrometer in the wavenumber range of $4000-400 \mathrm{~cm}^{-1}$. Hydrogen Nuclear Magnetic Resonance $\left({ }^{1} \mathrm{H}\right.$ NMR) spectra were carried out by using a Bruker AV-400 nuclear magnetic resonance spectrometer with chemical shift values in ppm downfield from TMS using $\mathrm{D}_{2} \mathrm{O}$ as solvents. The Liquid Chromatography Mass Spectrometry (LCMS) test was acquired on a Shimadzu LCMS-2020 instrument, 
the ion source was ESI, scanning range was $\mathrm{m} / \mathrm{z}$ 90 900, nebulizing gas flow was $1.5 \mathrm{~L} / \mathrm{min}$, dry gas flow was $15.0 \mathrm{~L} / \mathrm{min}$. The column was Ascentis Express C18, its length was $50 \mathrm{~mm}$, the internal diameter was $3.0 \mathrm{~mm}$, and description was $2.7 \mu \mathrm{m}$. Scanning electron microscopy (SEM) characterization of 2 wt \% THEED solution was obtained with a FEI Quanta 450 instrument, in the magnifying multiple ranges from $500 \times$ to $10000 \times$.

\subsection{Tests by Using Shale Samples}

The hot-rolling tests are carried out with shale samples to study the inhibitive ability of THEED, and the retention percentage will be measured after hot-rolling the samples for a specific amount of time at the set temperature. In the experiments, we selected the most representative shale inhibitors $\mathrm{KCl}$, mineral oil and NW-1 (a low molecular quaternary ammonium salt shale inhibitor), respectively, and compared the inhibition performance of THEED. The merits of the test consist of the fact that actual shale cuttings can be tested $[15,16]$. In this work, the obtained $(50 \pm 0.01 \mathrm{~g}) 40$-mesh shale samples were dried at $105^{\circ} \mathrm{C}$ for $24 \mathrm{~h}$, and rolling the shale samples in high-temperature aging tanks filled with $350 \mathrm{ml}$ (fresh water, $2.0 \mathrm{wt} \%$ inhibitor and mineral oil) solutions. The hot-rolling tests were carried out at $100{ }^{\circ} \mathrm{C}$ for $16 \mathrm{~h}$. When these experiments were completed, the shale samples was carefully rinsed and filtered by a 100 -mesh sieve, then dried to constant weight at $100{ }^{\circ} \mathrm{C}$, weighed, and from this we calculated the hot rolling recovery rate by Equation (1):

$$
V_{H}=\frac{R_{t}}{50} \times 100 \%
$$

where $R_{t}$ is the recycling mass, $V_{H}$ is the rolling recovery rate.

\subsection{Tests by Using Na-NMT}

Linear swelling tests were carried out in the laboratory by using CPZ-2 swelling apparatus (Dongying, China). The advantages of the linear swelling test are ease to evaluate the efficiency of an inhibitor to inhibit shale swelling and low cost, and the linear swelling test is a very popular method in the laboratory $[15,16]$. The select principles of $\mathrm{KCl}$, mineral oil and NW-1 have been explained in the "Tests by using shale samples" section. The artificial core was made by using $10 \pm 0.01 \mathrm{~g}, 40-\mathrm{mesh}$ Na-MMT powder, which was pressed tightly into a sample tube via a hydraulic compactor under $10 \mathrm{MPa}$ for $5 \mathrm{~min}$. The linear swelling rates over the whole experimental time at an atmospheric pressure condition were obtained.

\subsection{Particle Size Analysis Tests}

THEED with certain concentrations was added into WBDFs and stirred for $2 \mathrm{~h}$. Then, particle size analysis was measured with a laser diffraction technique (HORIBA, Kyoto, Japan). The operating temperature was $25^{\circ} \mathrm{C}$, the circulation speed was $2000 \mathrm{r} / \mathrm{min}$., the repeatability error was less than $3 \%$, the accuracy error less than $3 \%$, the ultrasonic system was $40 \mathrm{~Hz}, 70 \mathrm{~W}$, and the stirring speed was 100-475 rpm.

\subsection{Inhibition Mechanism Study}

\subsubsection{FT-IR Analysis}

$1 \mathrm{~g}$ THEED was added into $100 \mathrm{~mL}$ WBDFs and stirred for $2 \mathrm{~h}$, then centrifuged for $30 \mathrm{~min}$ and then we collected the precipitations. The precipitate was dried in a vacuum oven to constant weight at $50{ }^{\circ} \mathrm{C}$ for $24 \mathrm{~h}$, and samples (pure THEED, pure Na-MMT and THEED/Na-MMT complex) were analyzed in the wavenumber range of $4000-400 \mathrm{~cm}^{-1}$. The parameters of the infrared spectrometer were as follows: the spectral resolution was higher than $0.5 \mathrm{~cm}^{-1}$ and the wavelength accuracy was $0.1 \mathrm{~cm}^{-1}$. 


\subsubsection{XRD Analysis}

Samples were prepared as described in the "FTIR analysis" section, both the dry and wet precipitations were performed on an X Pert PRO MPD diffractometer (PANalytical B.V., Amsterdam, the Netherlands), the test angle was from $3^{\circ}$ to $10^{\circ}$, and the angle accuracy was 0.0001 .

\subsubsection{SEM Analysis}

SEM was investigated with the FEI Quanta 450 instrument (Thermo Fisher Scientific, Waltham, MA, USA), the range of the magnifying multiple was from 500 to 5000 , the samples were trimmed from the bottom of the filter cake, and the images were obtained at 120 500 Pa. The acceleration voltage of FEI Quanta 450 was $0.02-30 \mathrm{kV}$, the Probe current was $12 \mathrm{pA}-20 \mathrm{nA}$, abnd the stability ability was better than $0.2 \% / \mathrm{h}$.

\section{Results and Discussion}

\subsection{Characterizations of THEED}

FTIR, ${ }^{1} \mathrm{H}$ NMR and LCMS were utilized to determine the structure of THEED. Figure 2 shows the FTIR spectrum of THEED.

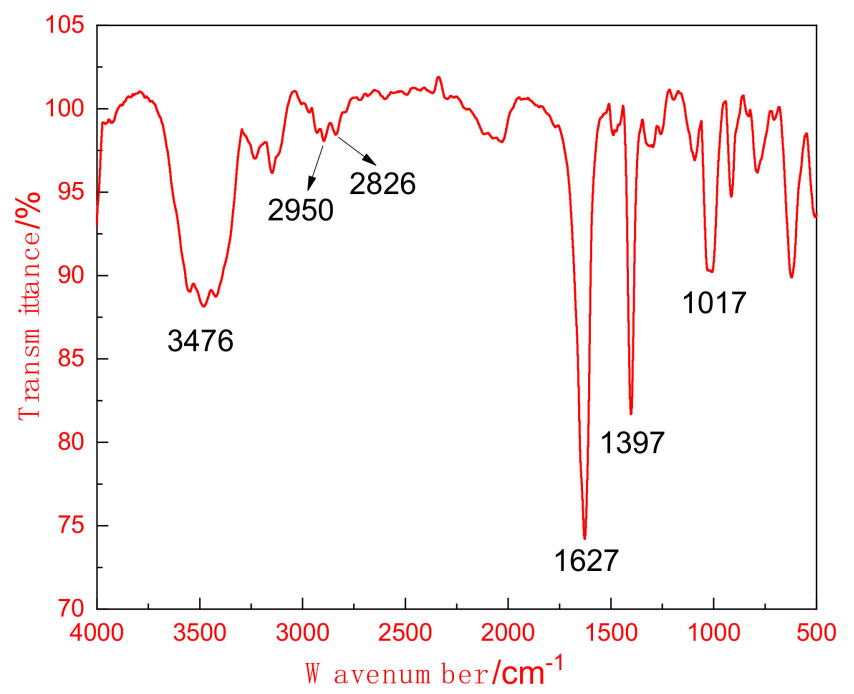

Figure 2. Fourier transform infrared spectrometry (FTIR) spectrum of THEED.

As shown in Figure 2, the peak at $3476 \mathrm{~cm}^{-1}$ was due to the $-\mathrm{OH}$ stretching of THEED. Peaks at approximately $2950 \mathrm{~cm}^{-1}$ and $2826 \mathrm{~cm}^{-1}$ was assigned to the stretching vibration bands $-\mathrm{CH}_{3}$ and $-\mathrm{CH}_{2}$, respectively. The recorded strong peak at $1627 \mathrm{~cm}^{-1}$ was assigned to the bending vibration of $\mathrm{NH}$ groups. The peaks at $1397 \mathrm{~cm}^{-1}$ and $1017 \mathrm{~cm}^{-1}$ were attributed to the characteristic absorption bands of the $\mathrm{CH}$ groups. The FTIR characterization spectrum contains all characteristic functional group absorption peaks of the target product, initially indicating the successful preparation of THEED.

${ }^{1} \mathrm{H}$ NMR and LCMS were further used to confirm the structure and purity of the target product, and the results are shown in Figures 3 and 4, respectively. As shown in Figure 3, the chemical shifts of $\mathrm{H}$ are: $4.67(\mathrm{~m}, 4 \mathrm{H}), \mathrm{C}-\mathrm{O}-\mathrm{H} ; 3.58(\mathrm{~s}, 8 \mathrm{H}), \mathrm{N}-\mathrm{C}-\mathrm{CH}_{2}-\mathrm{O} ; 2.66(\mathrm{t}, 8 \mathrm{H}), \mathrm{N}-\mathrm{CH}_{2}-\mathrm{C} ; 2.63(\mathrm{t}, 4 \mathrm{H})$, $\mathrm{N}-\mathrm{CH}_{2}-\mathrm{CH}_{2}-\mathrm{N}$. In the LCMS spectrum as displayed in Figure 4 , the purity of THEED was as high as $99.7 \%$. The FTIR, ${ }^{1} \mathrm{H}$ NMR and MS results all indicated that THEED has been successfully prepared. 


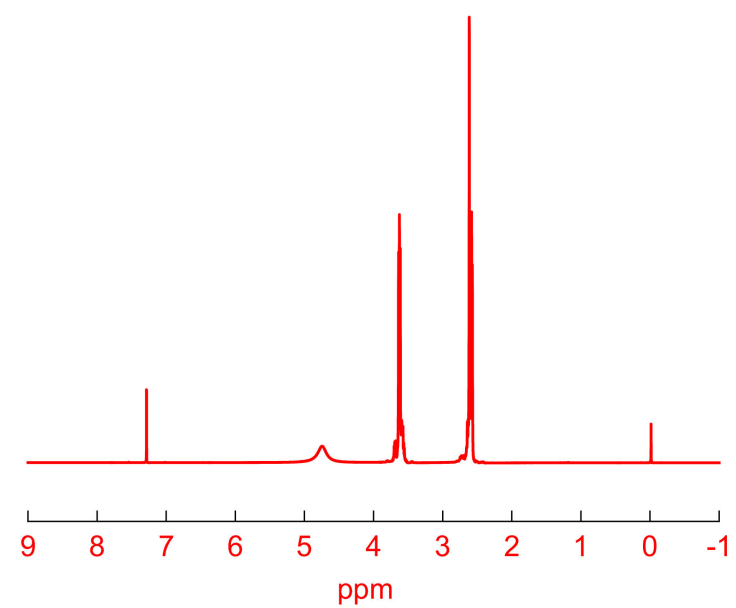

Figure 3. Hydrogen nuclear magnetic resonance $\left({ }^{1} \mathrm{H}\right.$ NMR) spectrum of THEED.

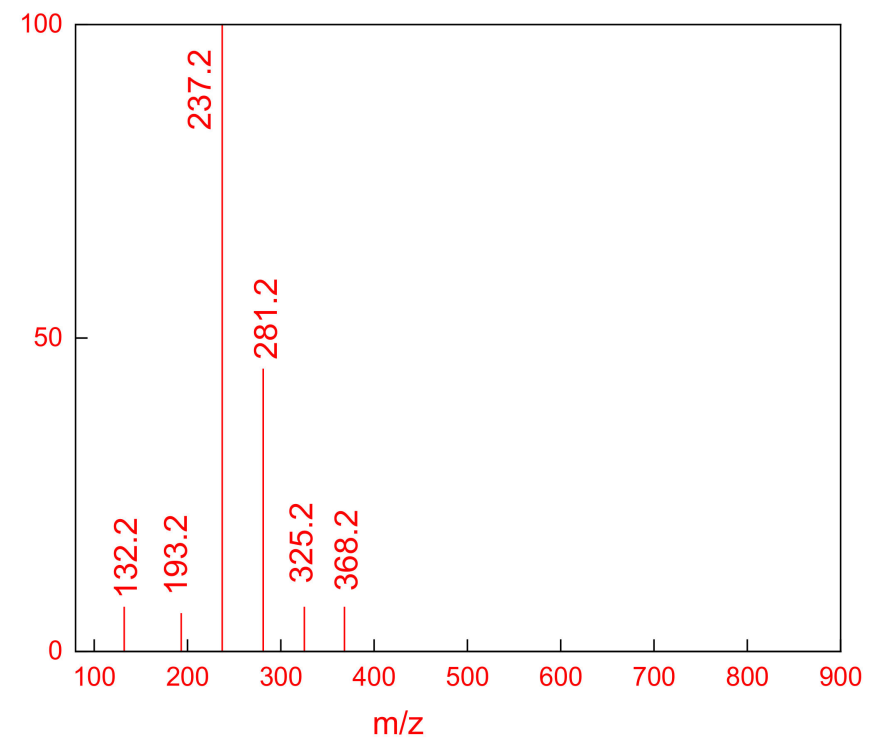

Figure 4. Mass Spectrometry (MS) spectrum of THEED.

The SEM characterization of $2.0 \mathrm{wt} \%$ THEED solutions is shown in Figure 5. The SEM image shown in Figure 5 reveals that an obvious gel-network microstructure was formed in $2.0 \mathrm{wt} \%$ THEED solution, indicating there was a pulling behavior with each other between THEED molecules, and thus the result of this study was similar to those reported in the literature [24,25].

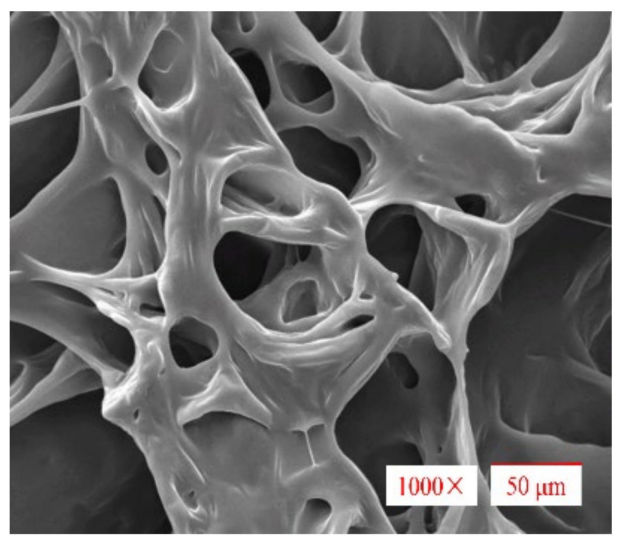

Figure 5. Scanning electron microscopy (SEM) image of THEED. 
Cross-linking effects were formed depending on the hydrogen bonds formed between the THEED molecules, and then present a three-dimensional network structure in THEED solutions, where the literature [26-28] interprets this pulling behavior as "self-assembly".

\subsection{Inhibition Property Evaluation}

\subsubsection{Hot-Rolling Recovery Tests}

The hot-rolling recovery tests were carried out $\mathrm{t} 100^{\circ} \mathrm{C}$ for $16 \mathrm{~h}$, as shown in Figure 6 .

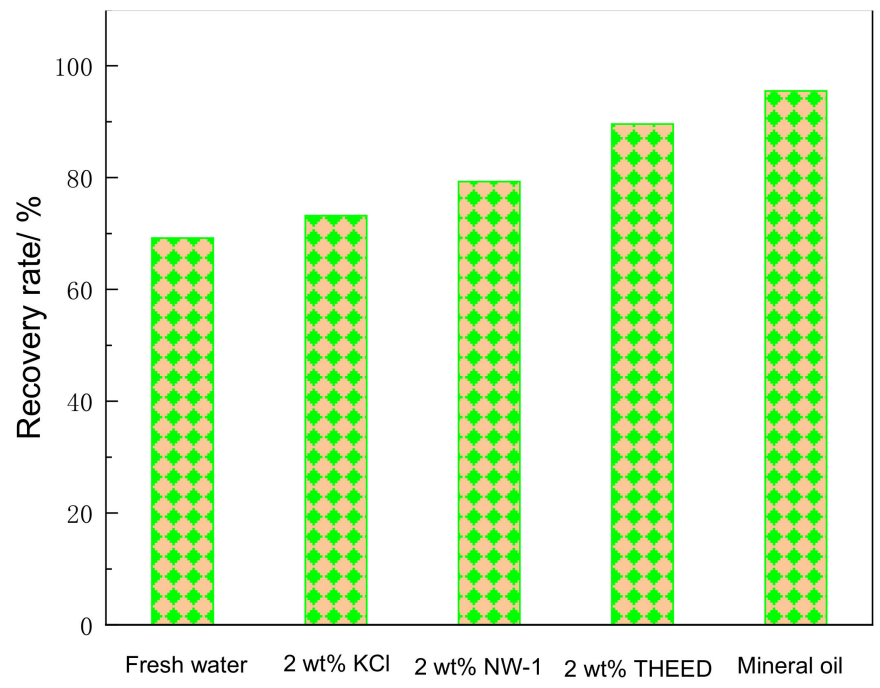

Figure 6. Hot-rolling recovery tests.

The hot-rolling recovery rate of the shale sample in fresh water was $69.2 \%$, indicating the comparatively high dispersion degree of this shale sample. With the addition of a different shale inhibitor, the rolling recovery rates have been improved to some extent. As there were very small amounts of expansive clay minerals in shale sample, it was difficult for $\mathrm{KCl}$ to enter into the crystal layers, and the recovery rate of shale in $2 \mathrm{wt} \% \mathrm{KCl}$ solutions increased slightly [29]. After adding quaternary ammonium salt NW-1, the rolling recovery rate increased to $79.3 \%$, indicating that NW-1 could play a certain role in inhibiting shale dispersion. THEED contains a large number of adsorptive hydroxyl functional groups, which can be firmly adsorbed on the surface of shale through hydrogen bonds and electrostatic forces [30,31], and could compress the shale diffusive electric double layer and replacing the interlayer water of shale. The hot-rolling recovery rate of the shale sample in $2 \mathrm{wt} \%$ THEED solutions was $89.6 \%$, and the recovery rate reached up to $95.5 \%$ in mineral oil, where there was the absence of water in mineral oil.

\subsubsection{Linear Swelling Tests}

In this part, linear swelling tests of the artificial shale core made by Na-MMT exposed to fresh water and different shale inhibitor solutions at room temperature and room pressure were studied, as shown in Figure 7. 


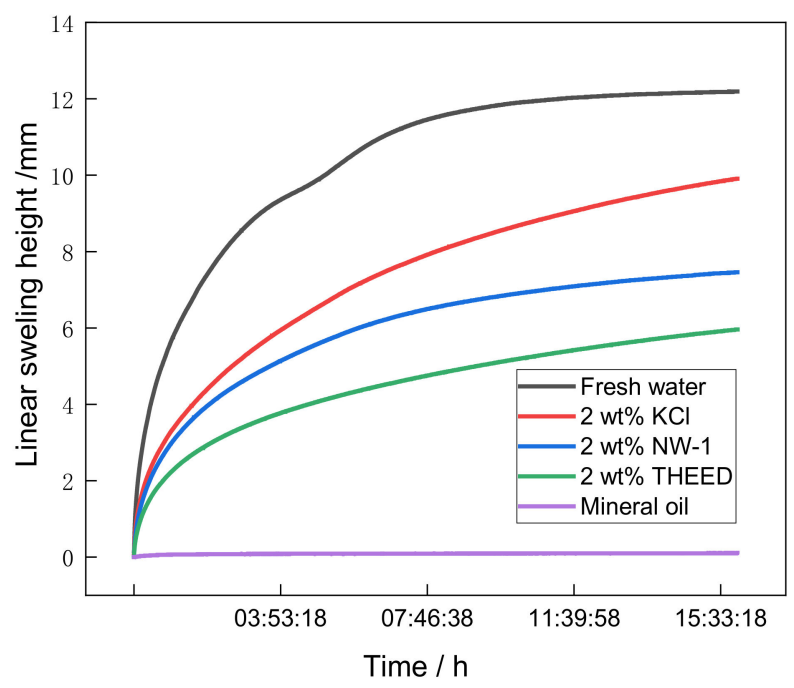

Figure 7. Linear swelling tests in different solution.

For all cases, the artificial shale core swelling height increased fast within the first $100 \mathrm{~min}$, and followed by a relatively slight increase within the rest test time. Within the whole experimental time, the swelling height in fresh water (base height) was significantly higher $(12.19 \mathrm{~mm})$ than other inhibitor solutions. $\mathrm{K}^{+}$is well known to be the preferred inorganic inhibitor in WBSFs, and the widely held belief is that the low hydration energy and small ionic radius ensure the embedding of $\mathrm{K}^{+}$into clay [29], as shown in Figure 8. NW-1 and THEED could enter the layer of the tetrahedral crystal of shale and compress the diffusion electric double layer of shale due to the small volume of both of them. Linear expansion height of shale core sample in $2.0 \mathrm{wt} \%$ THEED solution was just $4.74 \mathrm{~mm}$ after $16 \mathrm{~h}$, which was much lower than other cases in the study, except in mineral oil.

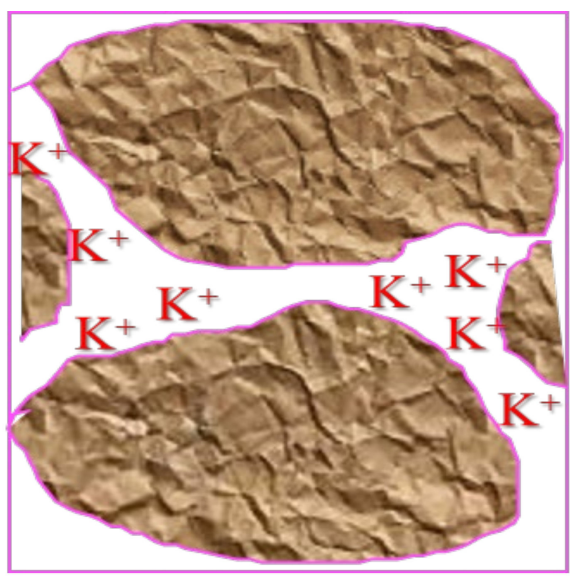

Figure 8. The clay inhibition mechanism of $\mathrm{K}^{+}$.

\subsubsection{Particle Distribution Tests}

It is well known that the negative charge surface of the shale is trendy to be neutralized by the positive charge of cations, and flocculation will occur when organic amine was added to the WBDFs. The shale particle disintegration test describes the hydration and disintegration of a shale sample when immersed in drilling fluid [32]. The inhibition performance was further evaluated by particle distribution tests.

As shown in Figure 9 for the case in fresh water, Na-MMT illustrated a tiny average particle size at $8.05 \mu \mathrm{m}$. In this work, the particle size of Na-MMT has been increased to $124 \mu \mathrm{m}$ in $2.0 \mathrm{wt} \%$ THEED solutions. The reasons may be as follows: THEED and Na-MMT are adsorbed together by hydrogen 
bonding and the Van der Waals force, resulting in the negative charge on the surface of Na-MMT being neutralized by THEED, so the diffusive electric double layer was being compressed, and resulting in the aggregation of Na-MMT.

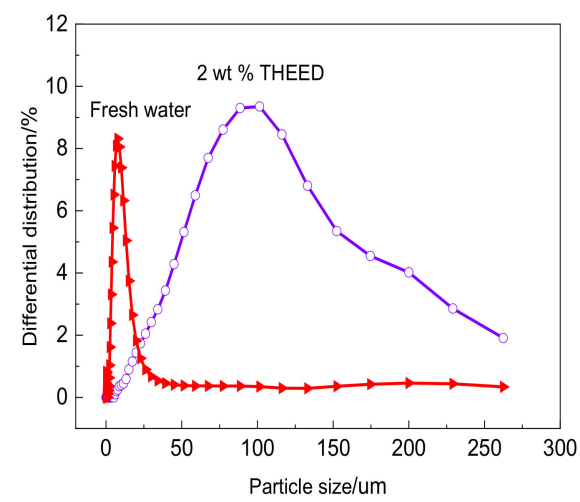

(a)

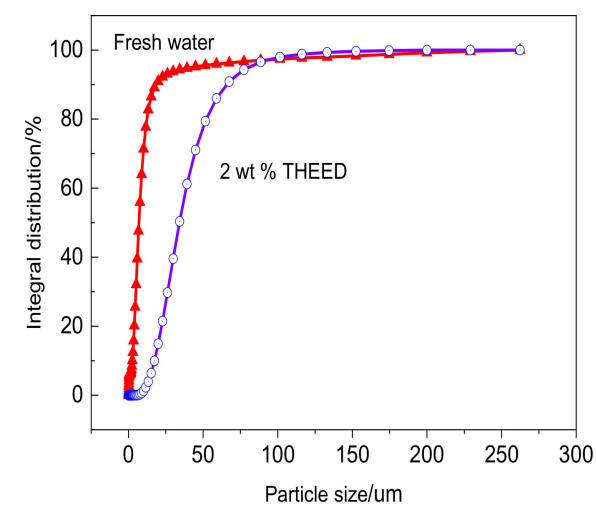

(b)

Figure 9. Particle distribution tests of THEED. (a) Differential distribution of samples. (b) Integral distribution of samples.

\subsection{Inhibition Mechanism Analysis}

The clay mineral composition of shale is very complicate, and the shale hydration expansion is just mainly caused by the swelling clay mineral (Na-MMT) in shale. In this work, we selected the highly expansive Na-MMT as the research object to analyze the inhibition mechanism of THEED.

\subsubsection{FT-IR Analysis}

FTIR is a sensitive technique to analyze the interaction type, configuration and local environment of Na-MMT modified by an intercalating agent. The inhibition mechanism has been analyzed by FTIR, as shown in Figure 10.

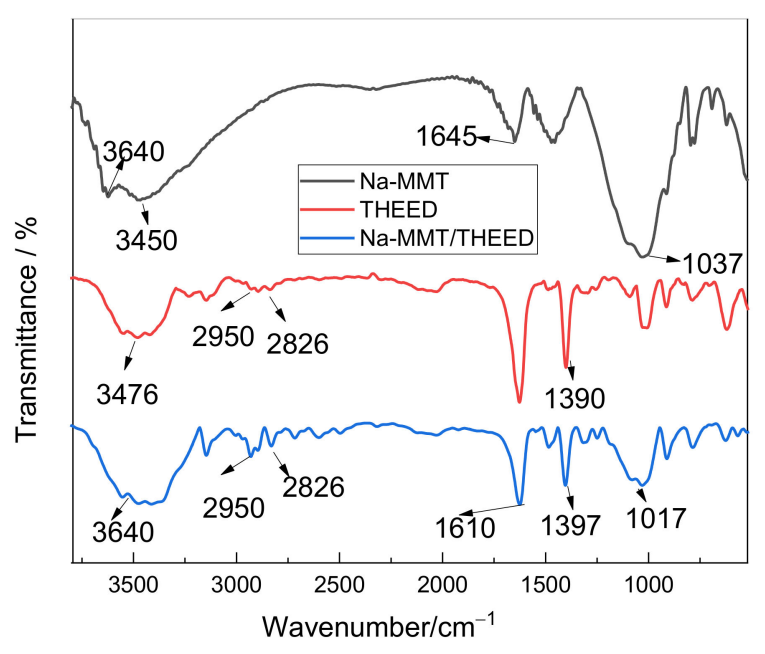

Figure 10. Inhibition mechanism analysis of THEED by FTIR.

The stretching vibrations of the structural $\mathrm{OH}$ groups occur at $3640 \mathrm{~cm}^{-1}$, while the $\mathrm{AlAlOH}$ and AlMgOH bending bands are observed at $921 \mathrm{~cm}^{-1}$ and $848 \mathrm{~cm}^{-1}$, respectively. The bands at $3450 \mathrm{~cm}^{-1}$ and $1645 \mathrm{~cm}^{-1}$ correspond to the $\mathrm{OH}$ stretching and bending vibrations of water molecules present in the montmorillonite [33-35]. 
A strong complex band at $1037 \mathrm{~cm}^{-1}$ is attributed to the stretching vibration of the Si-O groups of the tetrahedral sheets and the absorption bands at $525 \mathrm{~cm}^{-1}$ and $467 \mathrm{~cm}^{-1}$ belong to Si-O-Al and $\mathrm{Si}-\mathrm{O}-\mathrm{Si}$ bending vibrations, respectively. Some peaks belong to THEED, such as $3476 \mathrm{~cm}^{-1}$, $2950 \mathrm{~cm}^{-1}, 2826 \mathrm{~cm}^{-1}, 1627 \mathrm{~cm}^{-1}, 1397 \mathrm{~cm}^{-1}$ and $1017 \mathrm{~cm}^{-1}$, which were observed in the spectrum of the Na-MMT/THEED composite material, which indicated the successful adsorption of Na-MMT onto THEED. Adsorption bands at $1610 \mathrm{~cm}^{-1}$ corresponding to the adsorbed water was weaker when compared to the pure Na-MMT at $1645 \mathrm{~cm}^{-1}$, showing the significant decrease of adsorbed water in Na-MMT. This phenomenon is similar to that reported in the literature [35,36]. Decreased intensity was observed near the vibration band of $\mathrm{Si}-\mathrm{O}$ at $1037 \mathrm{~cm}^{-1}$ in Na-MMT, indicating that THEED could react with part of Si-O in Na-MMT.

\subsubsection{XRD Analysis}

Clay layers, mainly of the value of the basal spacing $\mathrm{d}_{(001)}$, were affected by water molecules, cationic compounds, adsorbents, intercalating agents, etc. [33]. The inhibition mechanism of THEED was further analyzed by X-ray diffractometry (XRD), and these results are shown in Figure 11.

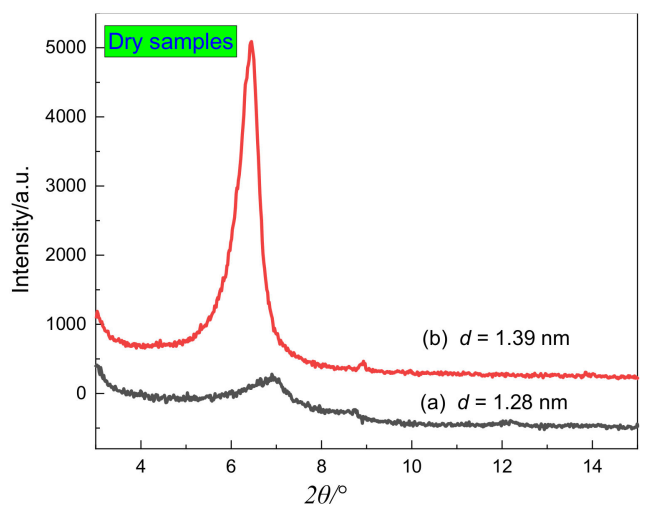

(A)

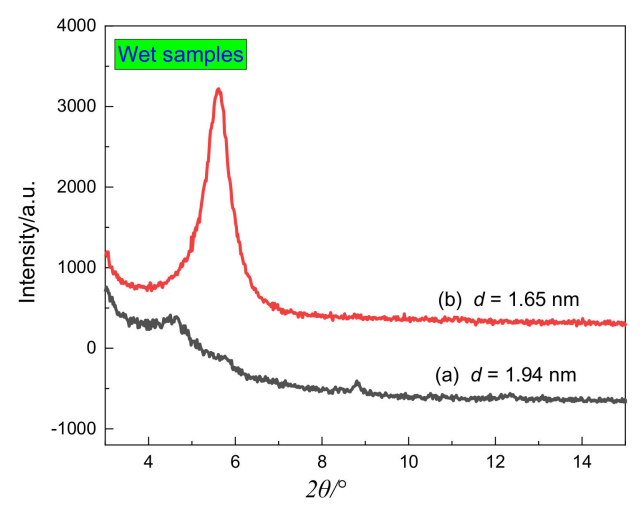

(B)

Figure 11. X-ray diffraction (XRD) patterns of samples: a pure Na-MMT; b Na-MMT/2 wt \% THEED.

(A) XRD curves of dry samples. (B) XRD curves of wet samples.

Figure 11 shows $X$-ray diffraction patterns of both dry and wet samples for the basal spacing $\mathrm{d}_{(001)}$ diffraction peaks of Na-MMT and Na-MMT/THEED. As displayed, it can be seen that the interlayer spacing of dry Na-MMT is $1.28 \mathrm{~nm}$, and the interlayer spacing has increased to $1.39 \mathrm{~nm}$ after the intercalation with $2 \mathrm{wt} \%$ THEED, which indicated that THEED had successfully entered and strongly adsorbed onto the interlayer of Na-MMT by the adsorption groups of THEED. In the wet cases, the interlayer spacing of Na-MMT in fresh water was $1.94 \mathrm{~nm}$, while $2.0 \mathrm{wt} \%$ THEED could reduce the interlayer spacing to $1.65 \mathrm{~nm}$. From the above results, we concluded that the amino group and hydroxyl groups of THEED can form hydrogen bonds with the Na-MMT surface, and replaced part of adsorbed water in the interlayer layer of Na-MMT and effectively inhibited the hydration expansion of Na-MMT.

\subsubsection{SEM Analysis}

SEM is a convenient technology to observe the morphological changes of Na-MMT composites. The obtained SEM images are demonstrated in Figure 12. 

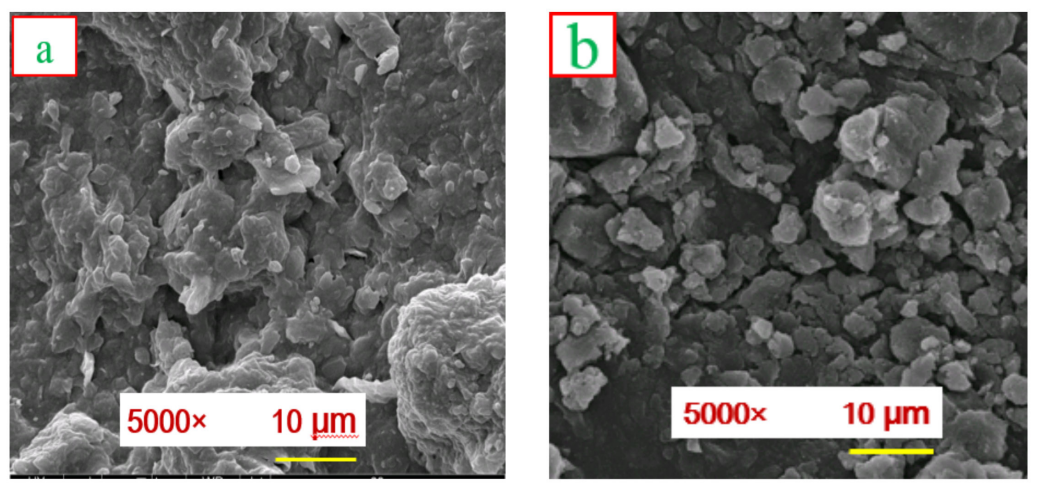

Figure 12. SEM analysis of samples. (a) The basic drilling fluids cake; (b) the Na-MMT/THEED cake.

Noticeable morphologic differences were observed in the different cake. The SEM image of basic drilling fluids cake showed the distinct wave-like, rough and homogeneously fluffy-shaped particles, as shown in Figure 12a. After treatment with $2 \mathrm{wt} \%$ THEED, the surface has become smooth and compact, the rough particles were stacked together in an excursive pattern to form slightly curled and crumpled edges (Figure 12b), which indicated the adsorptive reaction between THEED with Na-MMT. In addition, we also observed the appearance of micro-voids in the surface, which was probable due to the force decrease between Na-MMT sheets [37,38]. The bigger particle size has indicated that the intercalation happened between THEED and Na-MMT.

Through the inhibition property evaluation of THEED by a range of methods, and with reference to inhibition mechanism analysis in this work and in other work [39], we have proposed the inhibition mechanism of THEED on shale, as shown in Figure 13. With there being hydroxyl and amine functional groups in THEED, the polyhydroxy organic amine can enter into the shale crystal layer, compress the diffusion double layer of clay, pull the crystal layer together and prevent the hydration expansion and dispersion of shale.

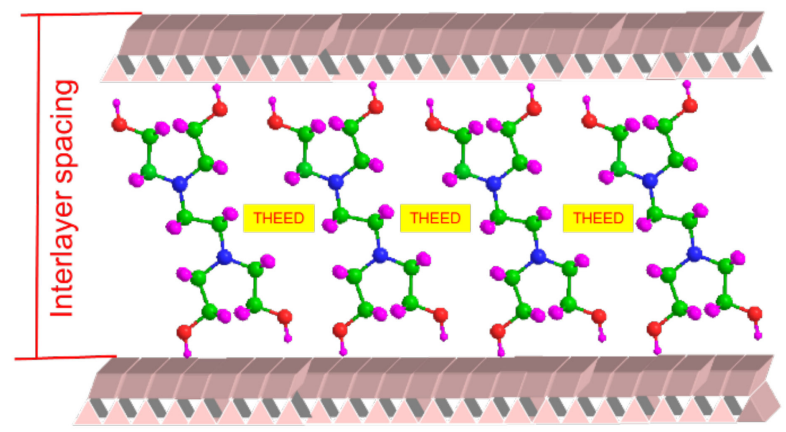

Figure 13. Inhibition mechanism analysis of THEED.

\section{Conclusions}

In conclusion, a novel polyhydroxy organic amine shale hydration inhibitor THEED was successfully synthesized in this work. Its structure was confirmed by FTIR, ${ }^{1} \mathrm{H}$ NMR and LCMS. Its inhibition performance was studied by several evaluation experiments, and results showed the outstanding shale hydration inhibition performance of THEED. We also utilized FTIR, XRD and SEM to study its inhibition mechanism, and it was found that THEED can be firmly adsorbed on the shale surface and enter into the interlayer of shale. In addition, THEED can change the appearance of Na-MMT by physical and chemical interaction with Na-MMT, and in that way achieve a good inhibition result. In summary, THEED shows excellent shale inhibition performance, and is expected to be applied in WBDFs. 
Author Contributions: Conceptualization, W.D. and X.W.; Formal Analysis, M.S.; Investigation, G.C.; Writing-Original Draft Preparation, J.Z.; Writing-Review \& Editing, M.S.; Supervision, W.D. and M.S.; Project Administration, W.D.; Funding Acquisition, W.D.; and all authors wrote the paper. All authors have read and agreed to the published version of the manuscript.

Funding: The authors would like to thank the Open Fund (PLC20190703) of State Key Laboratory of Oil and Gas Reservoir Geology and Exploitation (Chengdu University of Technology), Open Fund (PLN201814) of the State Key Laboratory of Oil and Gas Reservoir Geology and Exploitation (Southwest Petroleum University), Open Fund (KFKT2019-13) of the Key Laboratory of Auxiliary Chemistry and Technology for Chemical Industry, Ministry of Education Shaanxi University of Science and Technology for their financial support. The authors also acknowledge the financial support of the Slovak Grant Agency VEGA (grant 2/0141/17) and the Slovak Research and Development Agency (grants APVV-15-0741 and APVV-18-0075).

Conflicts of Interest: The authors declare no conflict of interest.

\section{References}

1. Ma, Y.S.; Cai, X.Y.; Zhao, P.R. China's shale gas exploration and development: Understanding and practice. Petrol. Explor. Dev. 2018, 45, 589-603. [CrossRef]

2. Adesoye, K. Shale Characterization for Evaluating Shale-drilling Fluid Interaction. Master's Thesis, University of Oklahoma, Norman, OK, USA, 2009.

3. Shadizadeh, S.R.; Moslemizadeh, A.; Dezaki, A.S. A novel nonionic surfactant for inhibiting shale hydration. Appl. Clay Sci. 2015, 118, 74-86. [CrossRef]

4. Balaban, R.C.; Ferreira Vidal, E.L.; Borges, M.R. Design of experiments to evaluate clay swelling inhibition by different combinations of organic compounds and inorganic salts for application in water base drilling fluids. Appl. Clay Sci. 2015, 105-106, 124-130. [CrossRef]

5. Chen, S.Y.; Shi, Y.P.; Yang, X.Y.; Xie, K.Z.; Cai, J.H. Design and evaluation of a surfactant-mixed metal hydroxide-based drilling fluid for maintaining wellbore stability in coal measure strata. Energies 2019, 12, 1862. [CrossRef]

6. Ni, X.X.; Jiang, G.C.; Li, Y.Y.; Yang, L.L.; Li, W.Q.; Wang, K.; Deng, Z.Q. Synthesis of superhydrophobic nanofluids as shale inhibitor and study of the inhibition mechanism. Appl. Surf. Sci. 2019, 484, 957-965. [CrossRef]

7. Jain, R.; Mahto, V.; Sharma, V.P. Evaluation of polyacrylamide-grafted-polyethylene glycol/silica nanocomposite as potential additive in water based drilling mud for reactive shale formation. J. Pet. Sci. Eng. 2015, 26, 526-537. [CrossRef]

8. Moslemizadeh, A.; Shadizadeh, S.R.; Moomenie, M. Experimental investigation of the effect of henna extract on the swelling of sodium bentonite in aqueous solution. Appl. Clay Sci. 2015, 105-106, 78-88. [CrossRef]

9. Uranta, K.G.; Rezaei-Gomari, S.; Russell, P.; Hamad, F. Studying the effectiveness of polyacrylamide (PAM) application in hydrocarbon reservoirs at different operational conditions. Energies 2018, 11, 2201. [CrossRef]

10. Jia, H.; Huang, P.; Wang, Q.X.; Han, Y.G.; Wang, S.Y.; Zhang, F.; Pan, W.; Lv, K.H. Investigation of inhibition mechanism of three deep eutectic solvents as potential shale inhibitors in water-based drilling fluids. Fuel 2019, 244, 403-411. [CrossRef]

11. Xuan, Y.; Jiang, G.C.; Li, Y.Y.; Wang, J.S.; Geng, H.N. Inhibiting effect of dopamine adsorption and polymerization on hydrated swelling of montmorillonite. Colloids Surf. A 2013, 422, 50-60. [CrossRef]

12. Rana, A.; Arfaj, M.K.; Saleh, T.A. Advanced developments in shale inhibitors for oil production with low environmental footprints-A review. Fuel 2019, 247, 237-249. [CrossRef]

13. Wilson, M.J.; Wilson, L. Clay mineralogy and shale instability: An alternative conceptual analysis. Clay Miner. 2014, 49, 127-145. [CrossRef]

14. Ahmed, H.M.; Kamal, M.S.; Al-Harthi, M. Polymeric and low molecular weight shale inhibitors: A review. Fuel 2019, 251, 187-217. [CrossRef]

15. Stephens, M.; Gomez-Nava, S.; Churan, M. Laboratory Methods to Assess Shale Reactivity with Drilling Fluids; AADE-2009-NTCE-11-04; American Association of Drilling Engineers. National Technical Conference \& Exhibition: New Orleans, LA, USA, 2009.

16. Oort, E.V.; Hoxha, B.B.; Hale, A. How to Test Fluids for Shale Compatibility; AADE-16-FTCE-77; American Association of Drilling Engineers. The AADE Fluids Technical Conference and Exhibition: Houston, TX, USA, 2016. 
17. Anderson, R.L.; Ratcliffe, I.; Greenwell, H.C.; Williams, P.A.; Cliffe, S.; Coveney, P.V. Clay swelling-A challenge in the oilfield. Earth-Sci. Rev. 2010, 98, 201-216. [CrossRef]

18. Teixeira, G.T.; Lomba, R.F.T.; Francisco, A.D.D.S.; da Silva, J.F.C.; Nascimento, R.S.V. Hyperbranched polyglycerols, obtained from environmentally benign monomer, as reactive clays inhibitors for water-based drilling fluids. J. Appl. Polym. Sci. 2014, 131, 40384-40391. [CrossRef]

19. Du, W.C.; Pu, X.L.; Sun, J.S.; Luo, X.; Zhang, Y.; Li, L. Synthesis and evaluation of a novel monomeric amine as sodium montmorillonite swelling inhibitor. Adsorpt. Sci. Technol. 2018, 36, 655-668. [CrossRef]

20. Jain, R.; Mahto, V. Evaluation of polyacrylamide/claycomposite as a potential drilling fluid additive in inhibitive water based drilling fluid system. J. Petrol. Sci. Eng. 2015, 133, 612-621. [CrossRef]

21. Gholami, R.; Elochukwu, H.; Fakhari, N.; Sarmadivaleh, M. A review on borehole instability in active shale formations: Interactions, mechanisms and inhibitors. Earth-Sci. Rev. 2018, 177, 2-13. [CrossRef]

22. Salles, F.; Douillard, J.M.; Bildstein, O.; Gaudin, C.; Prelot, B.; Zajac, J.; Van Damme, H. Driving force for the hydration of the swelling clays: Case of montmorillonites saturated with alkaline-earth cations. J. Colloid Interface Sci. 2013, 395, 269-276. [CrossRef]

23. Zhao, X.; Qiu, Z.S.; Zhang, Y.J.; Zhong, H.Y.; Huang, W.A.; Tang, Z.C. Zwitterionic polymer P (AM-DMC-AMPS) as a low-molecular-weight encapsulator in deepwater drilling fluid. Appl. Sci. 2017, 7, 594. [CrossRef]

24. Lin, C.Y.; Li, S.X.; Chen, M.; Jiang, R. Removal of congo red dye by gemini surfactant $\mathrm{C}_{12}-4-\mathrm{C}_{12} \cdot 2 \mathrm{Br}-\mathrm{modified}$ chitosanhydrogel beads. J. Disper. Sci. Technol. 2017, 38, 46-57. [CrossRef]

25. Zhao, W.W.; Wang, Y.L. Coacervation with surfactants: From single-chain surfactants to Gemini surfactants. Adv. Colloid Interfaces 2017, 239, 199-212. [CrossRef] [PubMed]

26. Yang, C.P.; Song, Z.Z.; Zhao, J.J.; Hu, Z.Y.; Zhang, Y.; Jiang, Q.Z. Self-assembly properties of ultra-long-chain gemini surfactants bearing multiple amide groups with high performance in fracturing fluid application. Colloids Surf. A: Physicochem. Eng. Asp. 2017, 523, 62-70. [CrossRef]

27. Menger, F.M.; Littau, C.A. Gemini-surfactants: Synthesis and properties. J. Am. Chem. Soc. 1991, 113, 1451-1452. [CrossRef]

28. Li, R.Q.; Yan, F.M.; Zhang, J.L.; Xu, C.F.; Wang, J.B. The self-assembly properties of a series of polymerizable cationicgemini surfactants: Effect of the acryloxyl group. Colloid Surf. A 2014, 444, 276-282. [CrossRef]

29. Boek, E.S.; Coveney, P.V.; Skipper, N.T. Monte carlo molecular modeling studies of hydrated Li-, Na-, and K-smectites: Understanding the role of potassium as a clay swelling inhibitor. J. Am. Chem. Soc. 1995, 117, 12608-12617. [CrossRef]

30. Huang, X.; Shen, H.K.; Sun, J.S.; Lv, K.H.; Liu, J.P.; Dong, X.D.; Luo, S.J. Nanoscale laponite as a potential shale inhibitor in water based drilling fluid for stabilizing wellbore stability and mechanism study. ACS Appl. Mater. Interfaces 2018, 10, 33252-33259. [CrossRef]

31. Caglar, B.; Topcu, C.; Coldur, F.; Sarp, G.; Caglar, S.; Tabak, A.; Sahin, E. Structural, thermal, morphological and surface charge properties of dodecyltrimethylammonium-smectite composites. J. Mol. Liq. 2016, 1105, 70-79. [CrossRef]

32. Suter, J.L.; Coveney, P.V.; Anderson, R.L.; Greenwell, H.C.; Cliffe, S. Rule based design of clay-swelling inhibitors. Energy Environ. Sci. 2011, 4, 4572-4586. [CrossRef]

33. Muayad, E.; Laurence, N.W.; Georg, G.; Meyer, T.; Schafmeister, M.T.; Kruth, A.; Testrich, H. Synthesis of hydroxy-sodalite/cancrinite zeolites from calcite-bearing kaolin for the removal of heavy metal ions in aqueous media. Minerals 2019, 9, 484-494.

34. Tuchowska, M.; Wołowiec, M.; Soli’nska, A.; Kościelniak, A.; Bajda, T. Organo-modified vermiculite: Preparation, characterization, and sorption of arsenic compounds. Minerals 2019, 9, 483. [CrossRef]

35. Slaný, M.; Jankovič, L'.; Madejová, J. Structural characterization of organo-montmorillonites prepared from a series of primary alkylamines salts: Mid-IR and near-IR study. Appl. Clay Sci. 2019, 176, 11-20. [CrossRef]

36. Madejová, J.; Sekeráková, L'.; Bizovská, V.; Slaný, M.; Jankovič, L'. Near-infrared spectroscopy as an effective tool for monitoring the conformation of alkylammonium surfactants in montmorillonite interlayers. Vib. Spectrosc. 2016, 84, 44-52. [CrossRef]

37. Li, M.C.; Ren, S.X.; Zhang, X.Q.; Dong, L.L.; Lei, T.Z.; Lee, S.Y.; Wu, Q.L. Surface-chemistry-tuned cellulose nanocrystals in a bentonite suspension for water-based drilling fluids. ACS Appl. Nano Mater. 2018, 1, 7039-7051. [CrossRef] 
38. Li, M.C.; Wu, Q.L.; Song, K.L.; French, A.D.; Mei, C.T.; Lei, T.Z. pH-responsive water-based drilling fluids containing bentonite and chitin nanocrystals. ACS Sustain. Chem. Eng. 2018, 6, 33783-33795. [CrossRef]

39. Vryzas, Z.; Kelessidis, V.C. Nano-based drilling fluids: A review. Energies 2017, 10, 540. [CrossRef]

(c)

(C) 2020 by the authors. Licensee MDPI, Basel, Switzerland. This article is an open access article distributed under the terms and conditions of the Creative Commons Attribution (CC BY) license (http://creativecommons.org/licenses/by/4.0/). 